\title{
Flexible Stochastic Frontier Approach to Predict Spot Speed in Two-Lane Highways
}

\author{
António Lobo; ${ }^{1}$ António Couto ${ }^{2}$ and Carlos Rodrigues ${ }^{3}$
}

${ }^{1}$ PhD Candidate, University of Porto, Faculty of Engineering, Research Centre for Territory, Transports and Environment, Rua Dr. Roberto Frias, s/n, 4200-465 Porto, Portugal, Phone: +351 225082 161, Email: lobo@fe.up.pt.

${ }^{2}$ Assistant Professor, University of Porto, Faculty of Engineering, Research Centre for Territory, Transports and Environment, Rua Dr. Roberto Frias, s/n, 4200-465 Porto, Portugal, Phone: +351 225082 110, Email: fcouto@fe.up.pt.

3 Professor, University of Porto, Faculty of Engineering, Research Centre for Territory, Transports and Environment, Rua Dr. Roberto Frias, s/n, 4200-465 Porto, Portugal, Phone: +351 225081 973, Email: cmr@fe.up.pt.

\begin{abstract}
The approach to spot speed prediction in two-lane highways followed in this study aims to evaluate the effects of a comprehensive set of speed factors, with a special focus on the geometric characteristics of the road segment to which the element belongs. Two flexible models were developed for different types of roads based on a stochastic frontier formulation in which the maximum operating speed is estimated as a function of road geometrics and the one-sided disturbance accounts for diversity in driving behavior and vehicle characteristics, allowing the estimation of any percentile speed. The models are applicable to horizontal curves and tangents and consider both on-site characteristics and aggregated variables characterizing the road segment. The results show a clear influence of segment features on different percentile spot speeds, revealing that recent driving experience and expectations about the quality of the geometric design influence the way a driver approaches a specific road element. Additionally, this study contributes to addressing some of the limitations of existing speed models identified in
\end{abstract}


the literature.

CE Database Subject Headings: Traffic Speed, Highway and road management, Stochastic Models, Portugal.

Author keywords: Spot speed, Two-lane highways, Road design, Stochastic frontier modeling.

\section{Introduction}

Operating speed is one of the most important factors in the evaluation and monitoring of roadway infrastructures. Drivers' evaluations of travel time, cost, convenience, and efficiency determine their route choice and are strongly influenced by their perceptions of the operating speeds of different routes. Likewise, many road design guides have been gradually implementing the use of operating speed prediction tools in the definition of road geometric standards, recommending that designers select a design speed with respect to road class, topography, and land use without neglecting driver expectancy (TRB 2011). Recommendations on maintaining a constant design speed over a substantial length of roadway are not new to road designers, but have proven to be insufficient to reduce speed variations between consecutive geometric elements, i.e., to ensure satisfactory design consistency. By anticipating the operating speed estimation in the design phase, some attributes that are not directly related to the design speed but which have a relevant impact on the operating speed (e.g., the cross-section width) may be properly defined. Therefore, the relationship between design speed and operating speed is currently regarded as a means to improve design consistency and safety performance (Fitzpatrick et al. 2003).

The relevance of the operating speed for setting roadway geometrics and other essential studies, such as the evaluation of the level of service, speed limit definition, and safety analyses, are at the heart of several efforts conducted by the research community, public authorities, and road 
operators to adequately predict road operating speeds and study its main drivers under different contexts. Those efforts have resulted in a wide array of tools for speed modeling (Fitzpatrick et al. 2000a; TRB 2011) and design consistency evaluation (Krammes et al. 1995; Gibreel et al. 1999; Fitzpatrick et al. 2000b) that are used by practitioners worldwide. Several issues arise from the complexity of studying driving speeds, however, and questions about the most relevant speed determinants and measures are frequently debated among researchers. Most studies consider a limited number of factors to predict specific speed measures (e.g., the $85^{\text {th }}$-percentile speed), which is seen as a limitation of the existing speed models (TRB 2011).

This study introduces new spot speed prediction models that provide additional flexibility compared to existing models by considering the influence of road segment characteristics on the speeds practiced at a specific curve or tangent while also being capable of predicting any userspecified percentile. Therefore, the proposed models account for the interdependence between several on-site, upstream, and downstream geometric variables, and combine the speed effects of recent driving experience, instant response to road geometrics, and expectations about the road features. In addition, the Operating Speed Frontier Model (OSFM) formulation allows percentile speed estimation on the basis of an asymmetric disturbance term accounting for non-quantified factors, such as diversity in driving behavior, vehicle technology, and road environment.

This work builds on the authors' previous studies on operating speed modeling (Lobo et al. 2013; Lobo et al. 2014), bringing together the major accomplishments of those studies while enlarging their scope and applicability. The OSFM formulation was developed and successfully tested in Lobo et al. (2014). Compared to previous models, the new models combine the estimation of any percentile speed defined by the user with the consideration of the segment characteristics and allow speed predictions for roads with higher design speeds. For that purpose, the database was 
enlarged to cover all types of two-lane highways existing in Portugal, with design speeds ranging from 40 to $90 \mathrm{~km} / \mathrm{h}$. Two mathematical expressions are provided to predict spot speeds in roads with very different design standards, distinguishing roads with interchanges, without direct access to roadside properties, and overall design speeds of 80 to $90 \mathrm{~km} / \mathrm{h}$, which are usually classified in Portugal as Principal Itineraries or Complementary Itineraries (hereinafter called IP/IC roads), from roads with at-grade intersections, access to private properties, and lower design speeds, classified as National Roads (hereinafter called N roads).

This study addresses relevant issues noted by other researchers concerning the existing speed models (TRB 2011) specifically related to the limited applicability of models, the limitations of linear regression, and issues with data collection. The developed models aim to be flexible tools to support accurate speed predictions for a broader range of road conditions, contributing even further to improving speed prediction capabilities.

The remainder of the paper is structured as follows. First, the literature framework provides an overview of speed modeling practices and deficiencies in existing models. Then, the paper proceeds with the data description, which details the data collection procedures and the most relevant characteristics of the selected roads. The model description presents the OSFM formulation and the techniques used in model estimation. The model estimation presents two spot speed models obtained for different types of road. In the discussion of results, the effects of each variable used as speed predictor are analyzed, emphasizing the relevance of the road segment characteristics for different percentile speeds. The final section summarizes the main conclusions of this study. 


\section{Literature Framework}

There is a large body of published literature presenting several approaches to modeling operating speed. Despite some inconsistencies between different sources, the definitions of operating speed provided by the main reference manuals are generally consistent and accepted by practitioners worldwide. The reference manual A Policy on Geometric Design of Highways and Streets (Green Book) (AASHTO 2011) defines operating speed as the speed at which drivers operate their vehicles during free-flow conditions, recognizing the $85^{\text {th }}$-percentile of the speed distribution as the most frequently adopted operating speed measure. The Manual on Uniform Traffic Control Devices (MUTCD) (FHWA 2009) states that the operating speed may be represented by the average, pace, or $85^{\text {th }}$-percentile speeds. In turn, the Highway Capacity Manual (HCM) (TRB 2010) proposes the similar concept of free-flow speed and suggests its measurement by averaging the speed of the observed vehicles.

Reference manuals and national guides for road design usually define design and operating speeds for segments rather than for specific design elements. When speed measurements are not possible, the HCM (TRB 2010) suggests adopting a base free-flow speed based on the design speed, posted speed limit, or operating speeds observed in similar facilities. Then, the free-flow speed is estimated for each road by reducing the base free-flow speed for the effects of the crosssection width and density of access points. In national guidelines, other effects are considered for operating speed prediction according to the local conditions, as is the case with the curvature change rate (CCR) and pavement width in Germany (FGSV 1995), and the bendiness and mean visibility in the UK (HA 2002). In turn, the Green Book (AASHTO 2011) proposes different design speeds according to the road functional classification and limits the speed differences between consecutive design elements to ensure design consistency. The official approach in 
Portugal follows a similar procedure (JAE 1994).

Spot speed prediction has also been a concern for the researchers, who have developed several models. Most models are based on conventional linear regressions and estimate specific percentile speeds considering a more or less comprehensive set of predictors. The Transportation Research Circular E-C151 (TRB 2011) presents a good review of the existing speed models and their deficiencies.

The lack of flexibility among percentile-specific models is acknowledged as one of the main limitations of most studies. Tarris et al. (1996) referred that the loss of information due to speed data aggregation reduces the total variability and the nature of the variability associated with the regression function, which may bias the effects of road geometrics, proposing that modeling the entire free-flow speed distribution may help to overcome the problem. The only existing models that support a speed distribution were developed by Figueroa Medina and Tarko (2005). The models, obtained by ordinary-least-squares regressions, predict different percentile speeds that are represented by a linear combination of the mean and standard deviation of the speed distribution, distinguishing between the mean speed factors and the speed dispersion factors. In another study by Figueroa Medina and Tarko (2004), percentile-specific and site-specific random effects were included in the model formulation to avoid estimating biased parameters produced by unknown non-considered factors.

Despite also using the entire free-flow speed distribution, the authors' approach to percentile speed modeling (Lobo et al. 2014) is based on stochastic frontier models usually applied in the field of econometrics (Aigner et al. 1977; Meeusen and van der Broeck 1977). The OSFM is estimated using the maximum likelihood method to establish an upper speed frontier, which represents the speeds of the fastest free-flow drivers in good weather and pavement conditions as 
a function of road geometrics. Percentile speeds, representing deviations from the speed frontier attributed to non-quantified factors, such as the characteristics of drivers, vehicles, and the surrounding environment, are estimated through the cumulative function of the one-sided disturbance inherent to the model formulation.

Park and Saccomanno (2006) and Park et al. (2010) noted that few studies consider the interdependence between the speeds practiced in consecutive road elements. Thus, the frontier function used in this study considers on-site, upstream, and downstream geometric features as spot speed predictors. The exponential functional form accounts for the variations of the geometric effects with respect to the order of magnitude of speeds. Moreover, separate models are estimated for road types with very different design standards.

In terms of speed predictors, existing studies consider a wide array of variables characterizing the road geometry, environmental conditions, type of vehicle, and driver expectancy. The horizontal alignment is usually seen as the most important factor affecting speed, with some authors stating that the radius is the only variable producing a significant impact on driving speeds (Kanellaidis et al. 1990; Passetti and Fambro 1999; Misaghi and Hassan 2005).

Some authors noted that the vertical alignment has been less studied (Fitzpatrick et al. 2000a; Misaghi and Hassan 2005), perhaps due to its smaller impact on the speed of passenger cars. Nevertheless, studies by, e.g., Fitzpatrick et al. (2000a) and Gibreel et al. (2001) focused on the simultaneous effects of the horizontal and vertical alignments, proposing speed models categorized by vertical alignment conditions. Donnell et al. (2001) studied the primary influence of the grade on truck speeds, developing speed models for horizontal curves that account for the effects of the grades of the approach and departure tangents.

Roads' cross-sectional features were considered in studies such as Lamm and Choueiri (1987), 
Lamm et al. (1988), and Figueroa Medina and Tarko (2005). Melo et al. (2012) evaluated the speed reductions with respect to lane and shoulder widths using a driving simulator and compared the results with the HCM (TRB 2010).

Variables characterizing the entire road segment or just the upstream or downstream segments have been used to represent driver expectancy. McLean (1981) proposed the concept of desired speed to predict speeds on horizontal curves; the desired speed is influenced by the overall design standards, road function, trip purpose and length, and proximity to urban areas. Krammes et al. (1995) and Bonneson et al. (2007) used the speed on the approach tangent to represent the effects of recent driving experience on curve speed. The HCM (TRB 2010) proposes a speed reduction from the density of access points. The influence of the downstream alignment is frequently represented by parameters related to the sight distance (Andueza 2000; HA 2002). Other less used speed predictors include the element extension (Krammes et al. 1995; Voigt and Krammes 1996; Cardoso 1996; Schurr et al. 2002), the superelevation rate (Voigt and Krammes 1996; Gibreel et al. 2001; Bonneson et al. 2007), and the posted speed limit (Lamm et al. 1988; Schurr et al. 2002).

Despite the numerous speed factors reported in the literature, individual studies have usually found that significant effects on operating speeds are produced by limited sets of variables. Hassan (2004) and Nie and Hassan (2007) warned that the sites selected for speed measurements often lack variability in terms of road features or even preclude some of them, which may affect the validity and applicability of the models due to the excessive simplification of reality. The proposed OSFM formulation was developed to tackle the problem by taking into account a broad set of geometric effects and their interactions with the order of magnitude of speeds without neglecting the non-quantified factors, such as environmental conditions, driving behavior, and 
vehicle technology.

Model validity and applicability may also be affected by the sample size and data collection procedures. Nie and Hassan (2007) stated that the number of sites and the number of observations per site used in speed modeling is sometimes limited and that manual speed measurements can introduce bias errors because drivers may change their behavior if they perceive test equipment as speed enforcement. The cosine error associated with the use of radar guns is also a factor. To develop the models in this study, a great number of observations, approximately 23,000 , was used, corresponding to the amount of vehicle speeds observed in seven two-lane highways with distinct design standards. Moreover, speed data were collected using discreet automatic traffic counters installed at the roadside, taking special care to calibrate their positioning using a test vehicle.

The new models are applicable to both curves and tangents, addressing the concerns raised by Polus et al. (2000) and Fitzpatrick et al. (2000a) about the need for additional research on tangent speeds. Thus, the model may support design consistency evaluation in Portugal, providing an alternative procedure in the national guidelines (JAE, 1994).

\section{Data description}

To calibrate the new speed models, speed and road geometrics data were collected in seven Portuguese two-lane highways, five of which are classified as N Roads (N14, N101, N105-2, N206, and N222), and two as IP/IC roads (IP2 and IC5). Spot speed measurements were made in 112 geometric elements, 77 curves, and 35 tangents located in selected road segments that reach a total length of $240 \mathrm{~km}$. The selected sites are located outside urban areas, and the marginal land use varies from the complete absence of construction to the presence of some isolated buildings. Because the aim was to evaluate not only the speed effects of the geometric characteristics 
observed at the test sites but also the effects of recent driving experience and expectations about the forthcoming road alignment, separate speed measurements were made for each direction to properly account for the upstream and downstream segments. To ensure a homogenous sample for modeling purposes, the same number of 102 free-flow vehicles was considered per site and direction, following the HCM (TRB 2010) recommendation of a minimum of 100 speed values measured per site for operating speed studies, resulting in a total of 22,848 observations. The percentage of heavy vehicles traveling in the case study roads is estimated at approximately $10 \%$ of the total number of vehicles. Free-flow traveling is established between vehicles that are separated by at least 6 seconds, as found in a study by Lobo et al. (2011) conducted in Portuguese two-lane highways. Automatic traffic counters (VIACOUNT II) containing a Doppler radar sensor, a real-time clock, and integrated data memory were used to record vehicle speeds and passing time. The equipment was installed at the roadside at the approximate midpoint of the selected curves and tangents. To ensure reliable speed measurements, the positioning of the traffic counters was calibrated using instrumented vehicle of the Traffic Analysis Laboratory of the Faculty of Engineering of the University of Porto. Because drivers may change their behavior upon perceiving test equipment as speed enforcement, the use of this type of equipment is especially adequate because its presence is barely noticeable and it does not require the presence of an operator while in use. Speed measurements were performed during the day in clear weather conditions. The pavement of the selected roads was in good shape, without cracks or potholes and with clearly visible markings.

The geometric characteristics were assessed in field measurements and/or by consulting road construction plans. When the construction plans were not available, the GPS coordinates of the road were collected with the instrumented vehicle and used the data to reproduce the road 
alignment via CAD software. The radius, length, grade, lane width, shoulder width, and lateral clearance were collected to characterize each of the selected elements. The grade and crosssection features were defined by representative mean values observed at each site. The length was discarded due to high correlations with other variables.

To characterize the upstream segments, the number of junctions and the deflection angle of each curve contained in each segment were collected. The grade observed at all the upstream segments is consistent with a level to rolling nature of the terrain. The upstream grade never surpasses a $3 \%$ value for an extension of $1 \mathrm{~km}$ or more, although higher grades may be present locally, as is the case for some spot speed measurement elements. According to the HCM (TRB, 2010), only the segments not attaining such limited conditions must be analyzed as specific grades due to relevant speed reductions. Therefore, the gradient of the upstream segment was not included in the speed modeling. In this study, 1-km-long upstream segments were used.

Assuming that the effects of downstream segments are related to the geometric characteristics that a driver is able to observe in every moment, the radii of the curves located within the decision sight distance were collected to characterize those segments. The decision sight distance was defined according to the Portuguese guide for road design (JAE 1994) and depends on the operating speed concept used by the same manual.

The collected data on road geometrics were subject to a preliminary treatment to derive the speed predictors considered in the models' development. The data treatment included the transformation of the continuous variables in log terms to comply with the OSFM formulation (Lobo et al. 2014), as well as the creation of dummy variables to represent specific effects and/or to improve the model specifications. The speed predictors are described as follows:

- Dummy variable for curves (C) - Allows the use of the same mathematical expression for both 
types of geometric elements. $C$ introduces a scale factor affecting the baseline formulation established for tangents $(\mathrm{C}=0)$ to allow the estimation of curve speeds $(\mathrm{C}=1)$;

- Curve radius $(C \times \ln R)-$ Characterizes curves only. For tangents, this predictor is nullified by $C$

- Dummy variables for medium-to-severe upgrades and downgrades (GUP and GDN) Represents steeper hills; GUP and GDN are set to 1 if the ascending or descending grade is equal to or greater than $4 \%$, respectively, and to 0 otherwise. The aggregation of grade data in $G U P$ and GDN was made because of the non-significant results obtained with continuous variables in preliminary model test runs, which is probably associated with the predominating level to rolling nature of the terrain at the selected locations. Fitzpatrick et al. (2000a) obtained similar results but tested the grade as a blocking factor and obtained some differences for grades above 4\%;

- One-direction paved width $(\ln P W)$ - Represents the sum of lane and right shoulder widths;

- Extra lateral clearance (ln $E L C)$ - Represents the distance between the right shoulder external limit and any fixed object at the roadside;

- Bendiness $(\ln B)$ - Represents the sum of the deflection angles of the horizontal alignment per kilometer in the upstream road segment;

- Dummy variable for intersections or interchanges $(D D I)$ and density of intersections or interchanges $(D D I \times \ln D I)-D I$ represents the number of intersections or interchanges with other public roads per kilometer in the upstream road segment. Because DI is considered in log terms, the dummy variable $D D I$ was created to nullify the effects of $D I$ when no intersections are observed at the upstream segment (DDI $=1$ if $\mathrm{DI} \neq 0$; DDI $=0$ if $\mathrm{DI}=0)$. Both the individual effects of $D D I$ and the cross-effects between $D D I$ and $D I$ are considered in the model estimation;

- Dummy variable for constrained visibility $(C V)$ - Represents the limitations of driver visibility 
due to the characteristics of the horizontal alignment of the downstream road section. $C V$ is set to 1 if a driver is traversing a curve with a radius equal to or smaller than the absolute minimum radius (as defined by the Portuguese guidelines (JAE 1994)) or if there is such a curve within the decision sight distance, and set to 0 otherwise.

The statistics of the variables included in the models are shown in Tables 1 and 2 for $\mathrm{N}$ roads and IP/IC roads, respectively.

The prominent differences between $\mathrm{N}$ roads and IP/IC roads, which in this study led to the development of separate speed models, have a historical background. Until the 1970s, the primary goal of road construction in Portugal was to provide road connections between all the country's towns and villages. By focusing on spatial coverage while containing construction costs, the design principles followed at that time relegated the operational performance to a secondary plan; the design speed was usually highly dependent on the topography. The great majority of $\mathrm{N}$ roads in Portugal were built prior to the 1970s. In the 1980s, the country was experiencing a major social and economic shift due to the end of a period of political instability stemming from the 1974 revolution and Portugal's accession to the European Union. These transformations contributed to increased population mobility needs that the existing road network was no longer capable of supporting. With the spatial coverage of the entire territory almost accomplished, but facing increasing problems related to traffic flow and safety, since the 1980s, the Portuguese Government has promoted the construction of new freeways and 2-lane highways aimed to support faster and safer connections between the country's main cities and with the Spanish border. Most of the new two-lane highways have been classified as IP/IC roads, are compliant with up-to-date design standards, and represent an enormous step forward in the quality of road geometric alignments. Fig. 1 portrays the typical environment of $\mathrm{N}$ roads (Fig. 
1(a)) and IP/IC roads (Fig. 1(b)) though the representation of two case-study roads.

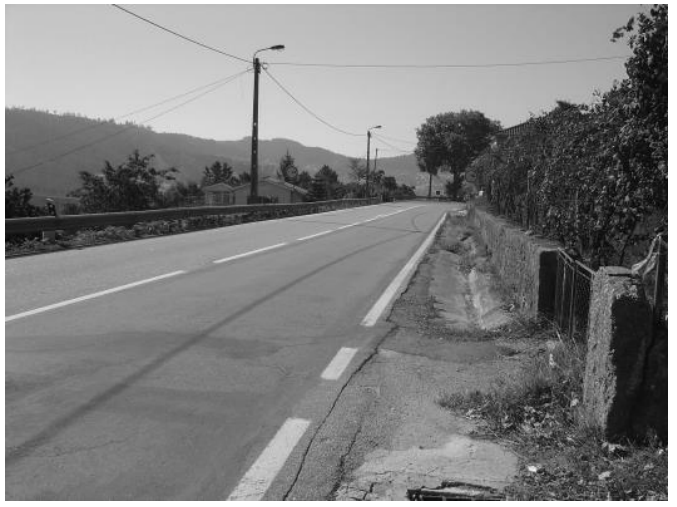

(a)

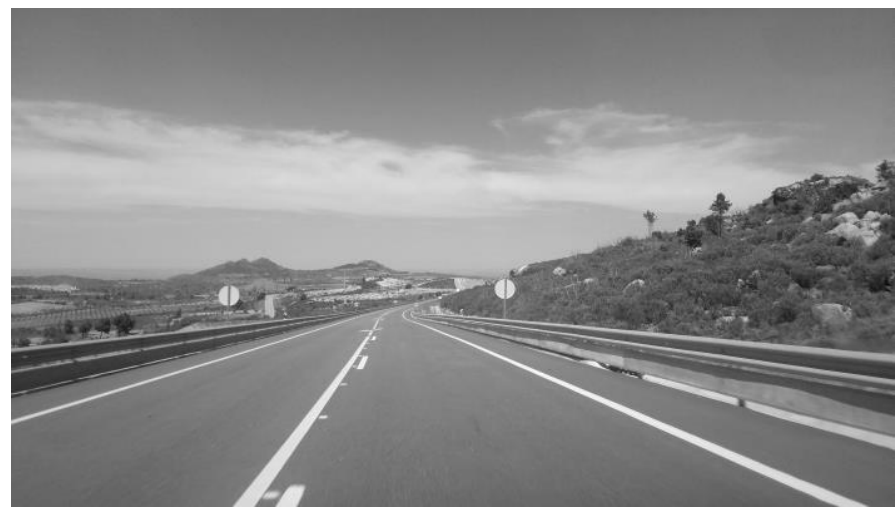

(b)

Fig. 1. (a) Example of N road: N101; (b) example IP/IC road: IC5

The five $\mathrm{N}$ roads selected in this study are representative of the diversity of $\mathrm{N}$ roads existing in Portugal. The design speeds vary from 40 to $70 \mathrm{~km} / \mathrm{h}$ and the junctions are, with a few rare exceptions, at-grade intersections. Direct access to roadside properties is allowed and variables such as the lateral clearance and the density of intersections exhibit significant variations with the marginal land use (see Table 1). Some curves have a smaller radius than the value recommended by the Portuguese guidelines currently in force (JAE 1994), which may bring negative consequences to the comfort and safety of car occupants and affects drivers' sight distance. The lane width is also sometimes smaller than the minimum value of $3.5 \mathrm{~m}$ defined by the same manual. 
Table 1. General Data on Curves and Tangents: N Roads

\begin{tabular}{|c|c|c|c|c|c|}
\hline Variable Description & Average & $\begin{array}{c}\text { Standard } \\
\text { Deviation }\end{array}$ & Minimum & Maximum & $\begin{array}{c}\text { Relative } \\
\text { Frequency }(\%)\end{array}$ \\
\hline \multicolumn{6}{|l|}{ Curves } \\
\hline Speed $(\mathrm{km} / \mathrm{h})^{\mathrm{a}}$ & 56.6 & 14.2 & 10.0 & 151.0 & $\mathrm{n} / \mathrm{a}$ \\
\hline $\mathrm{C}$ & $\mathrm{n} / \mathrm{a}$ & $\mathrm{n} / \mathrm{a}$ & $\mathrm{n} / \mathrm{a}$ & $\mathrm{n} / \mathrm{a}$ & 69.3 \\
\hline $\mathrm{R}(\mathrm{m})$ & 181.4 & 156.6 & 35.0 & 680.0 & $\mathrm{n} / \mathrm{a}$ \\
\hline GUP & $\mathrm{n} / \mathrm{a}$ & $\mathrm{n} / \mathrm{a}$ & $\mathrm{n} / \mathrm{a}$ & $\mathrm{n} / \mathrm{a}$ & 20.5 \\
\hline GDN & $\mathrm{n} / \mathrm{a}$ & $\mathrm{n} / \mathrm{a}$ & $\mathrm{n} / \mathrm{a}$ & $\mathrm{n} / \mathrm{a}$ & 20.5 \\
\hline PW (m) & 5.5 & 1.6 & 3.4 & $16.3^{b}$ & $\mathrm{n} / \mathrm{a}$ \\
\hline $\operatorname{ELC}(\mathrm{m})$ & 0.4 & 0.6 & 0.0 & 3.0 & $\mathrm{n} / \mathrm{a}$ \\
\hline B (degrees/km) & 239.7 & 172.4 & 13.8 & 854.7 & $\mathrm{n} / \mathrm{a}$ \\
\hline DDI & $\mathrm{n} / \mathrm{a}$ & $\mathrm{n} / \mathrm{a}$ & $\mathrm{n} / \mathrm{a}$ & $\mathrm{n} / \mathrm{a}$ & 94.3 \\
\hline DI (No./km) & 3.4 & 2.0 & 0.0 & 10.0 & $\mathrm{n} / \mathrm{a}$ \\
\hline $\mathrm{CV}$ & $\mathrm{n} / \mathrm{a}$ & $\mathrm{n} / \mathrm{a}$ & $\mathrm{n} / \mathrm{a}$ & $\mathrm{n} / \mathrm{a}$ & 52.5 \\
\hline \multicolumn{6}{|l|}{ Tangents } \\
\hline Speed $(\mathrm{km} / \mathrm{h})^{\mathrm{a}}$ & 62.4 & 14.5 & 11.0 & 130.0 & $\mathrm{n} / \mathrm{a}$ \\
\hline GUP & $\mathrm{n} / \mathrm{a}$ & $\mathrm{n} / \mathrm{a}$ & $\mathrm{n} / \mathrm{a}$ & $\mathrm{n} / \mathrm{a}$ & 16.7 \\
\hline GDN & $\mathrm{n} / \mathrm{a}$ & $\mathrm{n} / \mathrm{a}$ & $\mathrm{n} / \mathrm{a}$ & $\mathrm{n} / \mathrm{a}$ & 16.7 \\
\hline PW (m) & 4.9 & 1.4 & 3.1 & 9.6 & $\mathrm{n} / \mathrm{a}$ \\
\hline $\mathrm{ELC}(\mathrm{m})$ & 0.3 & 0.5 & 0.0 & 1.7 & $\mathrm{n} / \mathrm{a}$ \\
\hline B (degrees/km) & 182.9 & 140.0 & 8.9 & 593.5 & $\mathrm{n} / \mathrm{a}$ \\
\hline DDI & $\mathrm{n} / \mathrm{a}$ & $\mathrm{n} / \mathrm{a}$ & $\mathrm{n} / \mathrm{a}$ & $\mathrm{n} / \mathrm{a}$ & 92.6 \\
\hline DI (No./km) & 3.5 & 2.1 & 0.0 & 9.0 & $\mathrm{n} / \mathrm{a}$ \\
\hline $\mathrm{CV}$ & $\mathrm{n} / \mathrm{a}$ & $\mathrm{n} / \mathrm{a}$ & $\mathrm{n} / \mathrm{a}$ & $\mathrm{n} / \mathrm{a}$ & 20.4 \\
\hline
\end{tabular}

${ }^{a}$ Measured for free-flow vehicles $(g a p \geq 6 s)$.

$\mathrm{b}$ This exceptional value corresponds to one site featuring an unmarked parking area at the roadside.

Compared to the authors' previous research (Lobo et al. 2013; Lobo et al. 2014), the database was enriched in this study with data from two recently built IP/IC roads. These roads are representative of the two-lane IP/IC roads existing in Portugal featuring overall design speeds of 80 to $90 \mathrm{~km} / \mathrm{h}$. The undifferentiated treatment given in this study to IP and IC roads is related to the homogenous geometric features that characterize both types of roads and that set them apart from the $\mathrm{N}$ roads. In fact, the distinction between IP and IC roads is based on functional characteristics, such as the traffic volume, predominant types of journey, and interaction with the remaining network, rather than on geometric standards. The wider curves, no direct access to roadside properties and grade separation at junctions resulted in the observation of much higher values of average spot speed on IP/IC roads (see Table 2). 
Table 2. General Data on Curves and Tangents: IP/IC Roads

\begin{tabular}{|c|c|c|c|c|c|}
\hline Variable Description & Average & $\begin{array}{c}\text { Standard } \\
\text { Deviation }\end{array}$ & Minimum & Maximum & $\begin{array}{c}\text { Relative } \\
\text { Frequency }(\%)\end{array}$ \\
\hline \multicolumn{6}{|l|}{ Curves } \\
\hline Speed $(\mathrm{km} / \mathrm{h})^{\mathrm{a}}$ & 99.1 & 20.0 & 12.0 & 203.0 & $\mathrm{n} / \mathrm{a}$ \\
\hline $\mathrm{C}$ & $\mathrm{n} / \mathrm{a}$ & $\mathrm{n} / \mathrm{a}$ & $\mathrm{n} / \mathrm{a}$ & $\mathrm{n} / \mathrm{a}$ & 66.6 \\
\hline $\mathrm{R}(\mathrm{m})$ & 836.3 & 345.5 & 270.0 & 1650.0 & $\mathrm{n} / \mathrm{a}$ \\
\hline GUP & $\mathrm{n} / \mathrm{a}$ & $\mathrm{n} / \mathrm{a}$ & $\mathrm{n} / \mathrm{a}$ & $\mathrm{n} / \mathrm{a}$ & 34.4 \\
\hline GDN & $\mathrm{n} / \mathrm{a}$ & $\mathrm{n} / \mathrm{a}$ & $\mathrm{n} / \mathrm{a}$ & $\mathrm{n} / \mathrm{a}$ & 34.4 \\
\hline PW (m) & 5.2 & 0.5 & 4.9 & 6.4 & $\mathrm{n} / \mathrm{a}$ \\
\hline $\mathrm{ELC}(\mathrm{m})$ & 0.5 & 0.6 & 0.0 & 1.3 & $\mathrm{n} / \mathrm{a}$ \\
\hline B (degrees/km) & 49.0 & 26.6 & 13.1 & 119.1 & $\mathrm{n} / \mathrm{a}$ \\
\hline DDI & $\mathrm{n} / \mathrm{a}$ & $\mathrm{n} / \mathrm{a}$ & $\mathrm{n} / \mathrm{a}$ & $\mathrm{n} / \mathrm{a}$ & 16.1 \\
\hline DI (No./km) & 0.2 & 0.4 & 0.0 & 1.0 & $\mathrm{n} / \mathrm{a}$ \\
\hline $\mathrm{CV}$ & $\mathrm{n} / \mathrm{a}$ & $\mathrm{n} / \mathrm{a}$ & $\mathrm{n} / \mathrm{a}$ & $\mathrm{n} / \mathrm{a}$ & 6.5 \\
\hline \multicolumn{6}{|l|}{ Tangents } \\
\hline Speed $(\mathrm{km} / \mathrm{h})^{\mathrm{a}}$ & 102.4 & 21.4 & 12.0 & 183.0 & $\mathrm{n} / \mathrm{a}$ \\
\hline GUP & $\mathrm{n} / \mathrm{a}$ & $\mathrm{n} / \mathrm{a}$ & $\mathrm{n} / \mathrm{a}$ & $\mathrm{n} / \mathrm{a}$ & 31.3 \\
\hline GDN & $\mathrm{n} / \mathrm{a}$ & $\mathrm{n} / \mathrm{a}$ & $\mathrm{n} / \mathrm{a}$ & $\mathrm{n} / \mathrm{a}$ & 31.3 \\
\hline PW (m) & 5.0 & 0.5 & 4.0 & 6.1 & $\mathrm{n} / \mathrm{a}$ \\
\hline $\operatorname{ELC}(\mathrm{m})$ & 0.5 & 0.5 & 0.0 & 1.2 & $\mathrm{n} / \mathrm{a}$ \\
\hline $\mathrm{B}($ degrees/km) & 25.3 & 27.4 & 0.0 & 100.2 & $\mathrm{n} / \mathrm{a}$ \\
\hline DDI & $\mathrm{n} / \mathrm{a}$ & $\mathrm{n} / \mathrm{a}$ & $\mathrm{n} / \mathrm{a}$ & $\mathrm{n} / \mathrm{a}$ & 6.3 \\
\hline DI (No./km) & 0.1 & 0.2 & 0.0 & 1.0 & $\mathrm{n} / \mathrm{a}$ \\
\hline $\mathrm{CV}$ & $\mathrm{n} / \mathrm{a}$ & $\mathrm{n} / \mathrm{a}$ & $\mathrm{n} / \mathrm{a}$ & $\mathrm{n} / \mathrm{a}$ & 6.3 \\
\hline
\end{tabular}

${ }^{\mathrm{a}}$ Measured for free-flow vehicles $($ gap $\geq 6 s)$.

\section{Model description}

The speed distribution observed at a particular road location reflects the dispersion of the practiced speeds that arises from different interactions between drivers, vehicles, and instant/permanent conditions of the road and the surrounding environment. In other words, practiced speeds may vary with a wide array of factors characterizing the three components of road transport: road, driver, and vehicle. Because the permanent characteristics of the road, mainly related to the geometric design, are the common denominator for all the drivers observed at that location, it is possible to state that the highest speed value is the least influenced by the speed-restrictive characteristics associated with the driver, vehicle, and road environment. In other words, the speed practiced by the fastest driver is mainly dependent on road geometrics.

The OSFM approach, first described and tested in Lobo et al. (2014), consists of applying a stochastic frontier model formulation, commonly associated with the econometric analysis, to 
estimate an upper speed frontier based on the total number of speed observations registered at all test sites. This speed frontier is a function of road geometrics characterizing the permanent conditions of the road, which are widely accepted by the scientific community as the main drivers influencing speeds and are usually less subjective and easier to measure than driver, vehicle, and environmental characteristics. The speed frontier resulting values correspond to the estimated speed for the fastest free-flow driver for each possible combination of geometric features under good weather and pavement conditions. Because the estimated frontier represents an upper limit of the operating speeds, it is hereafter referred to as maximum operating speed (Vmax). Note that $\operatorname{Vmax}$ is a newly introduced speed concept arising from the statistical processing of operating speed data; hence, it should not be confused with maximum speeds associated with imminent crash situations, such as skidding and overturning. Vmax holds constant for all vehicles traversing a given road element and is given by Eq. (1).

$\operatorname{Vmax}_{j}=\exp \left(\beta_{0}+\sum_{k=1}^{n_{k}} \beta_{k} \ln X_{j k}\right)$

where $V \max _{j}$ is the maximum operating speed in element $j, X_{j k}$ is the geometric feature $k$ of the road element $j$, and $\beta$ represents regression coefficients. The exponential formulation represents the assumed principle according to which the effects of geometric factors are not cumulative but are dependent on the order of magnitude of practiced speeds.

The main advantage of the OSFM lies in its capability to provide any percentile speed estimation from Vmax by means of an asymmetric disturbance. In addition to the normally distributed disturbance assumed in most regression models, which supports the stochastic nature of the speed frontier and represents random errors related to data collection and the model specification, the OSFM considers a second, asymmetrically distributed disturbance term that allows the estimation of speeds for drivers acting below the speed frontier Vmax for each 
combination of road geometrics. The asymmetric disturbance is suitable for representing the non-quantified speed factors related to the characteristics of vehicles, drivers, and the surrounding environment. Subsequently, the cumulative distribution function of the asymmetric disturbance allows the estimation of any percentile speed. In Lobo et al. (2014), an exponential distribution was proposed for the one sided disturbance, such as $f(u)=\theta \cdot \exp (-\theta u)$, where $\theta$ is the rate parameter of the exponential function. The cumulative function is given by $F(u)=1-\exp (-$ $\theta u$, and the inverse transform is $u=(-1 / \theta) \cdot \ln (1-F)$. Thus, the general form to estimate the $p$ th percentile speed at a given road location is shown in Eq. (2).

$V p_{j}=\operatorname{Vmax}_{j} \times \exp \left(\frac{1}{\theta} \ln p\right)$

where $V p_{j}$ is $p$ th percentile speed in element $j$ and $p$ is the percentile value $(0<p<1)$.

The OSFM is estimated using the maximum likelihood method, which is more efficient in managing asymmetric disturbances than the least squares estimator (Greene 2008). The best parameter estimation is obtained by maximizing the log-likelihood function represented in Eq.

$\ln L=N \ln \theta+\frac{N}{2} \theta^{2} \sigma_{v}^{2}+\theta \sum_{j=1}^{n_{j}} \sum_{i=1}^{n_{i}}\left(v_{i j}-u_{i j}\right)+\sum_{j=1}^{n_{j}} \sum_{i=1}^{n_{i}} \ln \Phi\left(-\frac{v_{i j}-u_{i j}}{\sigma_{v}}-\theta \sigma_{v}\right)$

where $L$ is the likelihood function, $N$ is the total number of observations, $\sigma_{v}$ is the standard deviation of the noise term, and $\Phi($.$) is the standard normal distribution function.$

\section{Model estimation}

To calibrate the new spot speed models for Portuguese two-lane highways, two stochastic frontier regressions based on Eq. (2) are performed between the speeds of the free-flow vehicles and the road geometrics, one regression using data from IP/IC roads and another using data from $\mathrm{N}$ roads. Model estimations are made with the help of the econometric software Limdep (Greene 
2007), using the maximum likelihood method. A preliminary single model estimation was tried using the complete dataset; however, several variables were not statistically significant. In the two-model approach, few variables are removed from the models due to the lack of statistical significance at 5\% level, namely $D D I$ in both models and GUP, ELC, and $D D I \times \ln D I$ in the IP/IC model. The regression modeling results are presented in Tables 3 and 4 for $\mathrm{N}$ roads and IP/IC roads, respectively.

Table 3. Results of the Stochastic Frontier Regression: N Roads

\begin{tabular}{lcc}
\hline Variable & Coefficient & Standard Error \\
\hline Constant & 4.360 & $0.016^{\mathrm{a}}$ \\
C & -0.694 & $0.016^{\mathrm{a}}$ \\
C $\times \ln$ R & 0.122 & $0.003^{\mathrm{a}}$ \\
GUP & -0.014 & $0.004^{\mathrm{a}}$ \\
GDN & 0.021 & $0.004^{\mathrm{a}}$ \\
ln PW & 0.079 & $0.007^{\mathrm{a}}$ \\
ln ELC & 0.008 & $0.001^{\mathrm{a}}$ \\
$\ln$ B & -0.027 & $0.002^{\mathrm{a}}$ \\
DDI $\times \ln$ DI & -0.036 & $0.003^{\mathrm{a}}$ \\
CV & -0.049 & $0.004^{\mathrm{a}}$ \\
\hline
\end{tabular}

Note: No. of observations $=17,952 ; \log$-likelihood $=2,026.760 ; \sigma_{u}=0.170 ; \sigma_{v}=0.149 ; \theta=5.880$.

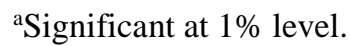

Table 4. Results of the Stochastic Frontier Regressions: IP/IC Roads

\begin{tabular}{lcc}
\hline Variable & Coefficient & Standard Error \\
\hline Constant & 4.636 & $0.050^{\mathrm{a}}$ \\
$\mathrm{C}$ & -0.608 & $0.072^{\mathrm{a}}$ \\
$\mathrm{C} \times \ln \mathrm{R}$ & 0.086 & $0.011^{\mathrm{a}}$ \\
GDN & 0.041 & $0.006^{\mathrm{a}}$ \\
$\ln$ PW & 0.070 & $0.031^{\mathrm{b}}$ \\
$\ln \mathrm{B}$ & -0.003 & $0.001^{\mathrm{b}}$ \\
$\mathrm{CV}$ & -0.055 & $0.015^{\mathrm{a}}$ \\
\hline
\end{tabular}

Note: No. of observations $=4,896 ; \log$-likelihood $=909.043 ; \sigma_{\mathrm{u}}=0.146 ; \sigma_{\mathrm{v}}=0.149 ; \theta=6.861$.

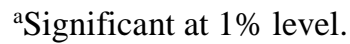

${ }^{\mathrm{b}}$ Significant at $5 \%$ level.

The model for spot speed prediction in N roads in Portugal is represented by Eqs. (4) and (5), used for the estimation of Vmax and the pth percentile speed $(V p)$, respectively.

$V \max =\exp (4.360-0.694 \times C+0.122 \times C \times \ln R-0.014 \times G U P+0.021 \times G D N+$ $+0.079 \times \ln P W+0.008 \times \ln E L C-0.027 \times \ln B-0.036 \times D D I \times \ln D I-0.049 C V)$ 
$V p=V \max \times \exp \left(\frac{1}{5.880} \times \ln p\right)$

Similarly, the model for speed prediction in IP/IC roads is given by Eqs. (6) and (7).

$V \max =\exp (4.636-0.608 \times C+0.086 \times C \times \ln R+0.041 \times G D N+0.070 \times \ln P W-$

$-0.003 \times \ln B-0.055 C V)$

$V p=\operatorname{Vmax} \times \exp \left(\frac{1}{6.861} \times \ln p\right)$

The OSFM formulation was tested and successfully validated in Lobo et al. (2014) by means of a comparison with other speed models existing in the literature. Nevertheless, it was tested in this study if the consideration of new sites and variables does not affect the accuracy of speed estimations, using the most known operating speed measure, i.e., the $85^{\text {th }}$-percentile speed (V85). First, the mean value of the observed V85 was computed for different groups of sites within the sample (V85o). All the tangents belonging to each type of road correspond to one group. In addition, some curves were grouped according to the type of road and range of radii, because the number of curves with the same radius were not enough to extract representative values of $V 85 o$. Subsequently, the models in Eqs. (4) to (7) were applied to estimate V85 for each group of sites, using the mean observed values of speed predictors (V85e). The results are presented in Fig. 2. 


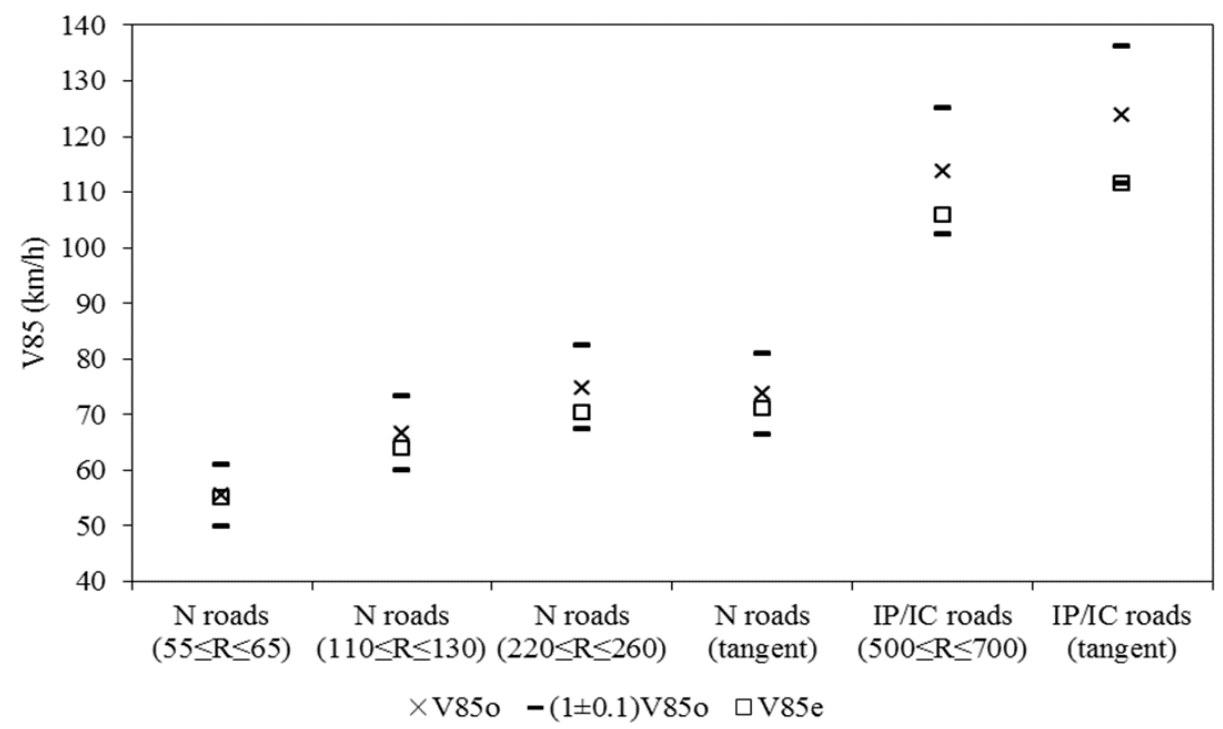

Fig. 2. Comparison between observed and estimated V85

The differences between $V 85 o$ and $V 85 e$ vary from $1.0 \%$ in curves of $\mathrm{N}$ roads with radii between 55 and $65 \mathrm{~m}$ to $9.9 \%$ in tangents of IP/IC roads. The application of the model for IP/IC roads result in larger speed deviations from the observed values compared to the model for $\mathrm{N}$ roads, probably because of an increased difficulty in the model's fit supported by speed data with higher dispersion. Nevertheless, for all test cases, V85e is within a margin of error of $10 \%$, which represents the maximum error usually assumed at spot speed data collection, indicating that the new models are still capable of providing satisfactory operating speed predictions.

\section{Discussion of results}

\section{Individual effects of speed predictors on spot speeds}

The model functional form allows the interpretation of the coefficients of the continuous variables as elasticities. The results in Tables 3 and 4 show that the on-site geometrics are the most important factors affecting the operating speed. The negative coefficients of $C$ reflect that operating speeds are lower in curves than in tangents, notwithstanding the value of $R$. 
Additionally, doubling the radius while keeping the remaining variables constant would increase Vmax in curves by $12 \%$ for $\mathrm{N}$ roads and $8 \%$ for IP/IC roads. Higher impacts occur in roads with lower design speeds, i.e., in roads with smaller radii values.

In terms of the vertical alignment, medium-to-severe downgrades would increase Vmax by $2.1 \%$ in $\mathrm{N}$ roads and by $4.1 \%$ in IP/IC roads. Medium-to-severe upgrades would reduce Vmax by $1.4 \%$ in $\mathrm{N}$ roads, not producing a statistically significant result for IP/IC roads, probably because operating speeds are much higher and passenger cars, which form approximately $90 \%$ of the collected sample, do not suffer a significant speed reduction in the ascending grades.

The results for the cross-sectional variables show that increasing $P W 10 \%$ while keeping the remaining variables constant would positively affect $\operatorname{Vmax} 0.8 \%$ and $0.7 \%$ for $\mathrm{N}$ roads and for IP/IC roads, respectively. An increase of $10 \%$ in $E L C$ while keeping the remaining variables constant would have a very small impact of $0.1 \%$ in Vmax for $\mathrm{N}$ roads. ELC did not produce a statistically significant result for IP/IC roads.

Regarding the upstream features, the negative elasticities of $B$ reveal that halving this variable would cause a speed increase of approximately $3 \%$ in $\mathrm{N}$ roads and $0.2 \%$ in IP/IC roads. These results are consistent with those obtained for the curve radius, i.e., improving the quality of the horizontal alignment produces higher impacts on the operating speed for roads with lower geometric standards.

In IP/IC roads, the density of interchanges did not produce statistically significant results, probably due to the lack of interchanges in the 1-km upstream segment of most observations and by the dubious impact of this type of junction on the speed of through traffic due to the absence of crossing conflict points. The density of intersections on $\mathrm{N}$ roads has negative effects on Vmax, as confirmed by the negative coefficient of $D D I \times \ln D I$. Doubling the number of intersections 
while keeping the remaining variables constant would produce a decrease in Vmax of approximately $4 \%$. The dummy variable $D D I$ as a standalone variable did not produce a statistically significant result because of the accessibility provided by $\mathrm{N}$ roads: only approximately $6 \%$ of the selected sites present no intersections at the corresponding upstream segments.

The downstream segment characterizing variable $C V$ shows that drivers reduce their speed when they see a tight curve downstream from their location. Reductions in Vmax are of approximately $5 \%$ for both types of road.

The rate parameter $\theta$ is lower for $\mathrm{N}$ roads $(\theta=5.880)$ than for IP/IC roads $(\theta=6.861)$. Therefore, percentile speed relative deviations from Vmax are smaller in the latter case, meaning that the higher the design speed, the lower the operating speed dispersion.

\section{Speed effects from the introduction of road segment characteristics}

To provide a better understanding of the spot speeds impacts caused by the characteristics of the upstream and downstream segments, a sensitivity analysis based on speed estimations for a set of generated scenarios is provided. Each scenario is characterized by a different combination of segment characteristics, varying between the sample minimum and maximum values to represent different harshness levels of the road alignment. The element geometrics are kept constant at the sample mean values. The scenarios are described as follows: S1 represents the best-case scenario, minimizing the negative effects and maximizing the positive effects of the upstream segment on spot speeds; S2 represents the average-case scenario, in which the upstream variables assume the sample mean values; $\mathrm{S} 3$ is the opposite of $\mathrm{S} 1$; $\mathrm{S} 4$ is the worst-case scenario, adding to $\mathrm{S} 3$ the effect of the downstream constrained visibility.

The models in Eqs. (4) to (7) were used to estimate $V 85$. The differences in $V 85$ between 
different scenarios provide a more tangible way to analyze the upstream and downstream effects than the coefficients/elasticities of variables affecting Vmax. Table 5 provides an overview of the scenarios and speed predictions for curves (V85c) and tangents (V85t).

Table 5. Scenarios for Sensitivity Analysis of the Segment Characteristics

\begin{tabular}{lccccc}
\hline $\begin{array}{l}\text { Scenario (Road } \\
\text { Type) }\end{array}$ & B & DI & CV & V85c (km/h) & V85t $(\mathrm{km} / \mathrm{h})$ \\
\hline S1 (N) & SMin & SMin & 0 & 75.9 & 80.6 \\
S2 (N) & SMean & SMean & 0 & 67.3 & 71.0 \\
S3 (N) & SMax & SMax & 0 & 62.5 & 66.5 \\
S4 (N) & SMax & SMax & 1 & 59.5 & 63.3 \\
S1 (IP/IC) & SMin & n/a & 0 & 109.0 & 114.3 \\
S2 (IP/IC) & SMean & n/a & 0 & 108.5 & 11.6 \\
S3 (IP/IC) & SMax & n/a & 0 & 108.2 & 11.2 \\
S4 (IP/IC) & SMax & n/a & 1 & 102.4 & 105.2 \\
\hline
\end{tabular}

Note: SMax = sample maximum; SMean = sample mean; SMin = sample minimum.

In absolute terms, the values of $V 85 c$ and $V 85 t$ show evidence of relevant contributions of the segment variables to the speed practiced at a given element, accounting for the driver's recent driving experience and expectations about the downstream geometric alignment. In Table 5, it is possible to observe that the estimated impacts on spot speeds due to the upstream factors present a variation of $14 \mathrm{~km} / \mathrm{h}$ from $\mathrm{S} 1$ to $\mathrm{S} 3$ in $\mathrm{N}$ roads. IP/IC roads present a much smaller variation of just $3 \mathrm{~km} / \mathrm{h}$, reflecting the homogeneity of characteristics of this type of road. Considering the constrained downstream visibility (S4), spot speeds may be affected by an additional value of 3 $\mathrm{km} / \mathrm{h}$ and $6 \mathrm{~km} / \mathrm{h}$, respectively. The speeds obtained in S2 are closer to S3 than to S1, i.e., in average terms, the geometric characteristics of the sample roads are closer to the more restrictive scenario. The results in Table 5 also show that speed reductions from $\mathrm{S} 1$ are greater in tangents than in curves, where drivers already travel at lower speeds due to the effects of the horizontal curvature. The upstream effects are more relevant in $\mathrm{N}$ roads, where the greater variability of road geometrics may induce some additional caution in spot speed choice. In turn, the downstream constrained visibility seems to affect more driving speeds on IP/IC roads, where 
such situations are uncommon and to a certain extent unexpected.

\section{Conclusions}

The increasing relevance of speed as a key indicator for design control and operational analysis of roadway infrastructures has strengthened the need for more versatile speed prediction tools. Despite the valuable contributions of road operations researchers, legislators, and practitioners to operating speed modeling, there is still a room to improve knowledge in this field and to fill the gaps identified in the literature (TRB 2011).

The main objective established for this study was to provide a flexible tool to provide accurate spot speed predictions in two-lane highways for a broad range of situations. To do so, the developed approach addresses some of the major limitations of existing speed models related to the preclusion of some relevant variables and the ability to estimate only specific percentile speeds; most of the existing spot speed models estimate the $85^{\text {th }}$-percentile speed as a function of local geometric features, mainly related to the horizontal curvature. Thus, the OSFM formulation was used to calibrate new spot speed models capable of predicting any user-specified percentile in curves or tangents on the basis of element and segment geometric characteristics. A deterministic speed frontier representing the maximum operating speed is established as a function of the road geometrics. The asymmetric disturbance reflects the differences in speed choice due to driving practices, vehicle type, and road environment. The cumulative function of the asymmetrical disturbance distribution allows the estimation of percentile speeds.

Model calibration was achieved using the entire speed distribution of approximately 23,000 freeflow vehicles collected on seven Portuguese roads with a great diversity of characteristics, resulting in two separate models for $\mathrm{N}$ roads, featuring intersections and accesses to roadside properties, and IP/IC roads, featuring interchanges and no marginal access. The results confirm 
the primary influence of the local effects produced by the horizontal and vertical alignments and the cross-section characteristics; however, the upstream and downstream features also play an important role in the way a driver approaches a specific curve or tangent. To shed light on the relevance of these variables, a set of scenarios reflecting different road conditions was created, allowing to observe that that the upstream characteristics, reflecting the recent driving experience, may reduce the spot speed in around $14 \mathrm{~km} / \mathrm{h}$, while the downstream constrained visibility, reflecting the driver's perception of the design quality of the downstream segment, may reduce the speed up to an additional $6 \mathrm{~km} / \mathrm{h}$.

The models were calibrated for the road conditions observed in Portugal, where it is possible to provide speed predictions for all types of non-mountainous two-lane highways. In other contexts, especially non-European countries, these models should be applied with caution. Nevertheless, the model formulation is sufficiently versatile to be replicated by practitioners across the globe for a broad range of road conditions. This research delivers one of the most flexible spot speed prediction tools to date, which considers the interactions between segment and on-site geometrics, is capable of predicting any percentile speed, is applicable to curves and tangents of different types of roads, and addresses some major limitations of such models identified in the literature concerning the formulation, calibration, and applicability, thus widely improving speed prediction capabilities. This study presents the authors' latest achievements in spot speed modeling and builds a basis for research on speed modeling in road segments planned for the near future.

\section{Acknowledgments}

This research was funded by the Portuguese Foundation for Science and Technology through PhD Grant SFRH/BD/71322/2010. 


\section{References}

AASHTO (American Association of State Highway and Transportation Officials). (2011). A Policy on Geometric Design of Highways and Streets, $6^{\text {th }}$ ed., Washington, DC.

Aigner, D., Lovell, C. A. K., and Schmidt, P. (1977). "Formulation and Estimation of Stochastic Frontier Production Function Models.” J. Econometrics, 6(1), 21-37.

Andueza, P. J. (2000). "Mathematical Models of Vehicular Speed on Mountain Roads." Transport. Res. Rec., 1701, 104-110.

Bonneson, J., Pratt, M., Miles, J., and Carlson, P. (2007). Development of Guidelines for Establishing Effective Curve Advisory Speeds, Texas Transportation Institute Research Report 05439-1, Texas A\&M University, College Station, TX.

Cardoso, J. P. L. (1996). Estudo das relações entre as caraterísticas da estrada, a velocidade e os acidentes rodoviários. Aplicação a estradas de duas vias e dois sentidos, PhD Dissertation, Technical University of Lisbon, Lisbon, Portugal.

Donnell, E. T., Ni, Y., Adolini, M., and Elefteriadou, L. (2001). "Speed Prediction Models for Trucks on Two-Lane Rural Highways.” Transport. Res. Rec., 1751, 44-55.

FGSV (Forschungsgesellschaft fuer Strassen-und Verkehrswesen). (1995). Richtlinien fuer die Anlage von Strassen, Teil: Linienfuehrung, Cologne, Germany (in German).

FHWA (Federal Highway Administration). (2009). Manual on Uniform Traffic Control Devices, U.S. Department of Transportation, McLean, VA.

Figueroa Medina, A. M., and Tarko, A. P. (2004). Reconciling Speed Limits with Design Speeds, Publication FHWA-IN-JTRP-2004/26. Joint Transportation Research Program, Indiana Department of Transportation and Purdue University, West Lafayette, IN. 
Figueroa Medina, A. M., and Tarko, A. P. (2005). "Speed Factors on Two-Lane Rural Highways in Free-Flow Conditions." Transport. Res. Rec., 1912, 39-46.

Fitzpatrick, K., Elefteriadou, L., Harwood, D. W., Collins, J. M., McFadden, J., Anderson, I. B.,

Krammes, R. A., Irizarri, N., Parma, K. D., Bauer, K. M., and Passetti, K. (2000a). Speed Prediction for Two-Lane Rural Highways, Publication FHWA-RD-99-171, Federal Highway Administration, U.S. Department of Transportation, McLean, VA.

Fitzpatrick, K., Wooldridge, M. D., Tsimhoni, O., Collins, J. M., Green, P., Bauer, K. M., Parma, K. D., Koppa, R., Harwood, D. W., Anderson, I., Krammes, R. A., and Poggioli, B. (2000b). Alternative Design Consistency Rating Methods for Two-Lane Rural Highways, Publication FHWA-RD-99-172, Federal Highway Administration, U.S. Department of Transportation, McLean, VA.

Fitzpatrick, K., Carlson, P., Brewer, M. A., Wooldridge, M. D., and Miaou, S. (2003). Design Speed, Operating Speed, and Posted Speed Practices, NCHPR Report 504, Transportation Research Board, Washington, DC.

Gibreel, G. M., Easa, S. M., Hassan, Y., and El-Dimeery, I. A. (1999). "State of the Art of Highway Geometric Design Consistency." J. Transp. Eng., 10.1061/(ASCE)0733947X(1999)125:4(305), 305-313.

Gibreel, G. M., Easa, S. M., and El-Dimeery, I. A. (2001). "Prediction of Operating Speed on Three-Dimensional Highway Alignments." J. Transp. Eng., 10.1061/(ASCE)0733947X(2001)127:1(21), 21-30.

Greene, W. H. (2007). Limdep Version 9.0: Econometric Modeling Guide, Econometric Software, Plainview, NY.

Greene, W. H. (2008). Econometric Analysis, $6^{\text {th }}$ ed., Prentice Hall, Upper Saddle River, NJ. 
HA (Highways Agency). (2002). Geometric Design is the Design Manual for Roads and Bridges, Vol. 6: Road Geometry, Section 1: Links, London, UK.

Hassan, Y. (2004). "Highway Design Consistency: Refining the State of Knowledge and Practice.” Transport. Res. Rec., 1881, 63-71.

JAE (Junta Autónoma de Estradas). (1994). Norma de Traçado, Almada, Portugal.

Kanellaidis, G., Golias, J., and Efstathiadis, S. (1990). "Driver's Speed Behavior on Rural Road Curves." Traffic Eng. Control, 31(7-8), 414-415.

Krammes, R. A., Brackett, Q., Shafer, M. A., Ottesen, J. L., Anderson, I. B., Fink, K. L., Collins, K. M., Pendleton, O. J., and Messer, C. J. (1995). Horizontal Alignment Design Consistency for Rural Two-Lane Highways, Publication FHWA-RD-94-034, Federal Highway Administration, U.S. Department of Transportation, McLean, VA.

Lamm, R., and Choueiri, E. M. (1987). "Recommendations for Evaluating Horizontal Design Consistency Based on Investigations in the State of New York." Transport. Res. Rec., 1122, 6878.

Lamm, R., Choueiri, E. M., Hayward, J. C., and Paluri, A. (1988). "Possible Design Procedure to Promote Design Consistency in Highway Geometric Design on Two-Lane Rural Roads.” Transport. Res. Rec., 1195, 111-122.

Lobo, A., Jacques, M. A. P., Rodrigues, C. M., and Couto, A. (2011). "Free-Gap Evaluation for Two-Lane Rural Highways.” Transport. Res. Rec., 2223, 9-17.

Lobo, A., Rodrigues, C., and Couto, A. (2013). "Free-Flow Speed Model Based on Portuguese Roadway Design Features for Two-Lane Highways.” Transport. Res. Rec., 2348, 12-18.

Lobo, A., Rodrigues, C., and Couto, A. (2014). "Estimating Percentile Speeds from Maximum Operating Speed Frontier.” Transport. Res. Rec., 2404, 1-8. 
McLean, J. (1981). "Driver Speed Behaviour and Rural Road Alignment Design.” Traffic Eng. Control, 22(4), 208-211.

Meeusen, W., and van den Broeck, J. (1977). "Efficiency Estimation from Cobb-Douglas Production Functions with Composed Error." Int. Econ. Rev., 18(2), 435-444.

Melo, P., Lobo, A., Couto, A., and Rodrigues, C. M. (2012). "Road Cross-Section Width and Free-Flow Speed on Two-Lane Rural Highways.” Transport. Res. Rec., 2301, $28-35$.

Misaghi, P., and Hassan, Y. (2005). "Modeling Operating Speed and Speed Differential on TwoLane Rural Roads.” J. Transp. Eng., 10.1061/(ASCE)0733-947X(2005)131:6(408), 408-418.

Nie, B., and Hassan, Y. (2007). "Modeling Driver Speed Behavior on Horizontal Curves of Different Road Classifications." TRB $86^{\text {th }}$ Annual Meeting Compendium of Papers, Transportation Research Board, Washington, DC, CD-ROM.

Park, P. Y., Miranda-Moreno, L. F., and Saccomanno, F. F. (2010). "Estimation of Speed Differentials on Rural Highways Using Hierarchical Linear Regression Models." Can. J. Civil Eng., 37(4), 624-637.

Park, Y. J., and Saccomanno, F. F. (2006). "Evaluating Speed Consistency Between Successive Elements of a Two-Lane Rural Highway.” Transport. Res. A-Pol., 40(5), 375-385.

Passetti, K. A., and Fambro, D. B. (1999). "Operating Speeds on Curves with and Without Spiral Transitions.” Transport. Res. Rec., 1658, 9-16.

Polus, A., Fitzpatrick, K., and Fambro, D. B. (2000). "Predicting Operating Speeds on Tangent Sections of Two-Lane Rural Highways." Transport. Res. Rec., 1737, 50-57.

Schurr, K. S., McCoy, P. T., Pesti, G., and Huff, R. (2002). "Relationship of Design, Operating, and Posted Speeds on Horizontal Curves of Rural Two-Lane Highways in Nebraska." Transport. Res. Rec., 1796, 60-71. 
Tarris, J. P., Poe, C. M., Mason Jr., J. R., and Goulias, K. G. (1996). "Predicting Operating Speeds on Low-Speed Urban Streets: Regression and Panel Analysis Approaches." Transport. Res. Rec., 1523, 46-54.

TRB (Transportation Research Board). (2010). Highway Capacity Manual 2010, Washington, DC.

TRB (Transportation Research Board). (2011). Transportation Research Circular E-C151: Modeling Operating Speed - Synthesis Report, Washington, DC.

Voigt, A. P., and Krammes, R. A. (1996). An Operational and Safety Evaluation of Alternative Horizontal Curve Design Approaches on Rural Two-Lane Highways, Texas Transportation Institute Research Report 04690-3, Texas A\&M University, College Station, TX. 